\title{
ASSESSORIA ABERTA COM VIÉS SOCIAL: UM ESTUDO DE CASO NO CENTRO DE REFERÊNCIA DE ASSISTÊNCIA SOCIAL
}

\section{OPEN ADVISORY WITH A SOCIAL BIAS: A CASE STUDY IN THE REFERENCE CENTER FOR SOCIAL ASSISTANCE}

\section{Suéllen Ramos}

Bacharel em Secretariado Executivo pela Universidade Estadual do Centro-Oeste do Paraná (UNICENTRO).

E-mail: suellen@agraria.com.br (Brasil)

\section{Ana Maria Kotzko}

Bacharel em Secretariado Executivo, Universidade Estadual do Centro-Oeste do Paraná (UNICENTRO). E-mail: anamkotzko@ hotmail.com (Brasil)

\section{Eloyse Gonçalves}

Bacharel em Secretariado Executivo, Universidade Estadual do Centro-Oeste do Paraná (UNICENTRO).

E-mail: eloyse.g@hotmail.com (Brasil)

\section{Raimundo Nonato Júnior}

Doutorado em Educação pela Universidade Federal do Ceará (UFC).

Professor Adjunto da Universidade Estadual do Centro-Oeste do Paraná (UNICENTRO).

E-mail: nonatorjr@gmail.com (Brasil) 


\section{ASSESSORIA ABERTA COM VIÉS SOCIAL: UM ESTUDO DE CASO NO CENTRO DE REFERÊNCIA DE ASSISTÊNCIA SOCIAL}

\section{RESUMO}

Este estudo teve como objetivo realizar uma análise sobre o Centro de Referência de Assistência Social (CRAS), sob a perspectiva das redes de assessoria que integram seu sistema de gestão. O estudo transcorre a estrutura organizacional do CRAS e a política de assistência social na forma de proteção social básica, articulando como meio de mediação, da gestão-sociedade às assessorias abertas. Utilizou-se o método dialético para reconhecer a realidade e transpô-la como conhecimento de forma exploratória e descritiva, no contexto da abordagem qualitativa, empregando-se técnicas de tipo de pesquisa bibliográfica, documental e entrevista. Os resultados obtidos apontam para três principais categorias: assessoria de serviços, gestão do CRAS e ordenação de rotinas, dialogadas junto aos conceitos de assessorias abertas eSecretariado Executivo. Assim, analisam-se as lacunas que emergem ao se revelar as problemáticas de gestão existentes no Centro de Referência de Assistência Social, sendo necessário suplantar modelos fechados e avançarna perspectiva das assessorias abertas, com o objetivo de mostrar a articulação gestão-sociedade do CRAS.

Palavras-Chave: Assessoria Aberta, Ciência da Assessoria, Gestão Social, Proteção Social Básica, Serviços. 


\title{
OPEN ADVISORY WITH A SOCIAL BIAS: A CASE STUDY IN THE REFERENCE CENTER FOR SOCIAL ASSISTANCE
}

\begin{abstract}
This study aimed to carry out an analysis of the Reference Center for Social Assistance (RCSA). The study unfolds the organizational structure of the RCSA and the policy of social assistance in the form of basic social protection, articulating as a way of mediation, from management-company to open advisories. The dialectical method was used in order to recognize the reality and convert it as knowledge in an exploratory and descriptive way, in the context of a qualitative approach, using the techniques of bibliographical reference, documentary and interview research. The results point to three main categories: services, management of RCSA and service orders, which are related to open advisories and to the Executive Secretariat. This way, the gaps that emerge when the existing problems are raised in the Reference Center of Social Assistance management are analyzed, under the prospect that their management can be analyzed through open advising, in order to show the joint management-company of RCSA from the perspective of advisories.
\end{abstract}

Keywords: Open Advisory, Secretarial Management Science. Social Management, Basic Social Protection, Servicing. 


\section{INTRODUÇÃO}

O conceito de assessoria aberta foi cunhado por Nonato Júnior (2009) para designar os trabalhos das assessorias executivas que ocorrem para além das dinâmicas organizacionais clássicas, manifestando-se em práticas sociais, programas culturais, projetos ambientais, atividades do terceiro setor e nas mais diversas práticas de gestão em organizações não convencionais. Nos últimos anos, diversas práticas de pesquisa que dialogam com o conceito de assessoria aberta podem ser observadas em temáticas de assessoria ligada aos movimentos sociais (Zampier, 2013), ao empreendedorismo secretarial (Recosec, 2011; Sousa \& Santos, 2012), à educação (Bauman \& Crotti, 2009), à extensão universitária (Crotti, 2010), atividades culturais (Luiz, 2010), a questões ambientais, sociais, estudo da língua estrangeira e da gestão do conhecimento (Oliveira, 2011).

Nesta perspectiva, Nonato Júnior (2009) concebe as assessorias abertas como instâncias gestoras de mediação entre temáticas de manifestação social e sua perspectiva de gestão em diversos espaços sociais, culturais, políticos e ambientais. Logo, a assessoria aberta é, desde sua concepção, uma proposta interdisciplinar e transdisciplinar, envolvendo tanto diversas áreas do conhecimento como relação entre saber científico e sociedade civil.

É a partir dessa perspectiva que se desenvolve o presente estudo, utilizando desta noção conceitual para abordar um campo ainda inexplorado pelos estudos de Secretariado Executivo: o Centro de Referência da Assistência Social (CRAS). Neste campo, interessa analisar as práticas de assessoria aberta utilizadas na gestão das equipes, atividades e tarefas do referido centro social.

A pesquisa buscou, também, elencar possíveis alterações e contribuições que o referido equipamento estatal trouxe para a população usuária dos serviços por meio de legislações e enfoque da assistência social no desenho do instrumento CRAS. Ademais, identificou intervenções possíveis de serem realizadas para que haja a efetivação da gestão das demandas sociais no CRAS e a gestão da instituição.

Para maior entendimento e compreensão da instituição CRAS no Estado brasileiro há a necessidade de buscar compreender alguns documentos importantes, dentre eles, cita-se: $\mathrm{O}$ Sistema Único de Assistência Social (Suas), criado no ano de 1993, como lei, e futuramente no ano de 2004 surge a proposta de haver a Política Nacional da Assistência Social (PNAS).

O CRAS é um órgão que trabalha sob a óptica da multidisciplinaridade, intersetorialidade e territorialidade, visando à redução e enfrentamento das mais diversas 
demandas que se apresentam no cotidiano dos indivíduos, suas famílias e no desenvolvimento social (Brasil, Suas/PR: Instrumentos Legais, s/d, p. 21).

O CRAS se configura em serviços prestados à comunidade de um determinado território, para atender às demandas sociais emergenciais que se apresentam a seus usuários de maneira a prevenir os riscos de vulnerabilidade social - trabalha diretamente interligado com vários setores e órgãos gestores- por meio de planejamento, acompanhamento, encaminhamentos, monitoramento e avaliações da rede sócia assistencial do território em que está inserido.

Essa lógica de funcionamento é permeada pela necessidade de aprimoramento contínuo da prestação dos serviços, por meio da relação entre gestão das demandas sociais e gestão institucional. Mediante este contexto, a assessoria aberta se faz presente, e se instaura a emergência de uma gestão mediadora das demandas sociais e de uma instituição. Essa mediação pode ser vista de várias formas, e uma delas são as assessorias abertas, pois é possibilitada no trabalho do profissional de Secretariado Executivo. De acordo com Nonato Júnior (2009, p. 157), “o trabalho empírico do profissional secretário é marcado pelo ato de assessorar, seja no âmbito operacional, tático, executivo, intelectual e interdisciplinar".

De acordo com Crotti (2010), o secretariado, no cerne das assessorias abertas, adota um perfil de diálogo na sociedade, possibilitando interligar realidades e conhecimentos. $\mathrm{O}$ desenvolvimento dos seus trabalhos não está voltado apenas ao âmbito empresarial, pois este profissional pode atuar nos diversos campos das ciências sociais aplicadas; onde houver gestão, haverá assessoria gestora, seja em espaços tradicionais ou abertos.

Nessa perspectiva, para analisar as assessorias abertas no CRAS é necessário analisar a articulação gestão-sociedade, por conta das demandas sociais que se apresentam no cotidiano dos profissionais e para uma intervenção objetiva que gere resultados para o enfrentamento das problemáticas que os indivíduos e a comunidade apresentam. Para tanto, é necessário analisar a rede de relações entre os serviços prestados e a sociedade, analisar como os profissionais veem essa articulação e os vários níveis de escalas envolvidas no contexto de sociedade, instituição, município, estado e União. É nesta perspectiva que este artigo é mobilizado a partir da seguinte indagação: em que perspectiva a gestão do CRAS pode ser analisada sob viés das assessorias abertas?

Dessa forma, tem-se o objetivo de analisar a articulação gestão-sociedade do CRAS na óptica das assessorias abertas, e a contribuição das assessorias abertas, prestando auxílio nos serviços ofertados pelo Centro, realizando: descrições sobre as atribuições/funções dos profissionais que estão na gestão do CRAS e, elencar as atividades rotineiras no exercício das 
funções levantadas; caracterizar os serviços prestados; analisar a gestão daquele centro a partir da assessoria aberta e, ainda, analisar a contribuição do profissional de Secretariado Executivo para projetos de natureza social. O campo de pesquisa foi um CRAS de município de médio porte, localizado na região centro-sul do estado do Paraná e os sujeitos da investigação são os quatro profissionais que compõem a rede gestora daquele espaço e trabalham nas atividades de cadastro, articulação, atendimento e prestação de serviços do centro.

Para bem compreender a realidade interdisciplinar em torno deste estudo, faz-se necessário pensar conceitos ligados a três questões principais, a saber: a política de assistência social no Brasil; o contexto do CRAS no município estudado, estado e União e a pesquisa social nas assessorias abertas.

\section{DISCUSSÃO TEÓRICA}

\subsection{A POLÍTICA DE ASSISTÊNCIA SOCIAL NO BRASIL}

O contexto histórico-social brasileiro vem marcado de grandes transformações, principalmente no âmbito socioeconômico. O Estado passa a assumir um papel funcional como regulador, com a finalidade de promover o desenvolvimento econômico e o bem-estar social, instaurando assim, um sistema de proteção social. (Santos, 1987, apud Silva e Silva Yasbek \& Giovanni, 2008, p. 26).

"A crescente pauperização e as políticas estatais constituem-se em um assunto que permeia os estudos de pesquisadores e profissionais envolvidos na área das políticas públicas do nosso país" (Yazbek, 1999, p. 36).

Um marco essencial no reordenamento do conceito de cidadania ocorre por meio da Constituição Brasileira de 1988 - época de grandes confrontos entre governo e sociedade civil, momento em que se pôde sentir uma mudança no quadro das políticas sociais, sob o contexto de redemocratização do país. A desestruturação do mercado de trabalho, o agravamento das condições socioeconômicas, as dificuldades dos segmentos pobres de acessarem os bens e serviços sociais, a falta de interação entre os setores governamentais, entre governo e sociedade, e a dificuldade em se manter as ações desenvolvidas. Surgem as políticas sociais com o objetivo de regular e amenizar os confrontos da classe trabalhadora com os capitalistas e o caráter de direito social passa a ser traduzido como benefício ao invés de caridade (Santos, 1987, apud Silva e Silva, Yasbek \& Giovanni, 2008).

Revista de Gestão e Secretariado - GeSec, São Paulo, v. 6, n. 3, p 46-69,set./dez. 2015. 
Para Couto (2006, p.183), o Estado deve ser supremo na criação de um sistema de garantia de direitos, visando a confrontar as demandas geradas pelas dificuldades enfrentadas pelo indivíduo na busca de viver com dignidade e a sociedade como um todo deve assumir um papel de parceria nesse enfrentamento de maneira participativa.

A efetivação de uma rede de atuação se torna essencial para que a gestão das políticas sociais se instaure de forma a garantir os direitos em um cenário de um projeto neoliberal, em que o Estado afirma sua posição de defensor do sistema, amenizador de conflitos, ou seja, um Estado que busca expandir o capital e gerar o desenvolvimento do país e de seus indivíduos, fundamentando-se na geração das políticas sociais como amenizadoras da pobreza.

Dessa forma, surge a necessidade de efetivar políticas de intervenção emergencial, de cunho participativo e de gestão descentralizada que realmente gerem resultados positivos, e se desvinculem da meritocracia, fazendo com que o indivíduo se torne protagonista de sua história e não mero coadjuvante, "uma empresa adepta do modelo de gestão em redes, atua com um sistema horizontal de hierarquia, entendida pela "descentralização de suas unidades e na crescente autonomia dada a cada uma delas".

Inicia-se a análise do CRAS para remeter à nova situação a que se expõe o Brasil com a assistência social como proteção social. No ano de 1988, quando a assistência social passa a fazer parte do tripé da seguridade social como política pública de direitos prevista na constituição federal, esta leva em conta, na sua matriz de serviços, as pessoas, as circunstâncias que se encontram e a família como elementos fundamentais de intervenção. "A assistência social será prestada a quem dela necessitar, independentemente de contribuição à seguridade social [...]”. (Brasil/ Constituição Federal, 1988, art. 203)

A assistência social inicia seu avanço no campo dos direitos, deixa de ser política meritocrática e passa a ser regulada por leis próprias e diretrizes que norteiam a política em sua implantação e implementação no campo da proteção social “[...] inicia seu trânsito para um campo novo: o campo dos direitos, da universalização dos acessos e da responsabilidade estatal.” (Brasil/PNAS, 2005, p.31).

Em dezembro de 1993 regulamenta-se a política de assistência social em sua Lei Orgânica da Assistência Social - Loas, Lei no 8.742, direcionando a um conjunto de ações em rede, concretizando a necessidade de um sistema integrado para alcançar os objetivos propostos pelareferi alei. (Brasil, Loas, 1993)

No ano de 2003, na Conferência Nacional da Assistência Social, decidiu-se pela construção e implementação do Sistema Único da Assistência Social - Suas. O objetivo 
fundamental da Conferência foi o de instaurar e organizar discussões sobre o tema na busca do desenvolvimento de reestruturação orgânica da Política de Assistência Social, potencializando “[...] os esforços políticos e administrativos necessários ao enfrentamento das grandes e crescentes demandas sociais" (Brasil, Suas/PR: Instrumentos Legais, s/d, p. 21). Sendo assim, publicou-se a Norma Operacional Básica 2005, que define as bases para a consolidação do Suas no Brasil.

A tipificação nacional de serviços sócio assistenciais prevê equipamentos para a realização dos serviços de assistência. Tais equipamentos estão previstos da seguinte forma:

\begin{abstract}
As proteções sociais, básica e especial, serão ofertadas precipuamente no Centro de Referência de Assistência Social (CRAS) e no Centro de Referência Especializado de Assistência Social (CREAS), respectivamente, e pelas entidades sem fins lucrativos de assistência social. (Brasil, Lei n. 8.742/93, art. $6^{\circ}-\mathrm{C}$ )
\end{abstract}

Em 2009, mediante resolução $n^{\circ}$ 109/2009, aprova-se a tipificação nacional dos serviços sócio assistencial que organiza o Suas em níveis de serviços: serviços de proteção básica, serviços de proteção social especial de média complexidade, serviço de proteção social especial de alta complexidade.

\title{
2.2 CRAS - MUNICÍPIO, ESTADO E UNIÃO
}

O CRAS é o equipamento de proteção social básica que "tem como objetivos prevenir situações de risco por meio do desenvolvimento de potencialidades e aquisições, e o fortalecimento de vínculos familiares e comunitários." (Brasil/PNAS, 2005, p. 33).

Cada município deve identificar sua demanda e território de abrangência de vulnerabilidade social (território de abrangência é aquele delimitado a partir dos locais de residência das famílias referenciadas) e nele implantar um CRAS, de acordo com a NOBRH/Suas deve ser instalado em área central, de fácil acesso e o mais próximo possível do público a ser atendido.

Os elementos que devem ser considerados para levantamento de demanda de vulnerabilidade social são fatores que se relacionam com condições habitacionais, locais com presença de públicos prioritários, infraestrutura, configurações familiares diversificadas e observância de atendimento de outras políticas públicas na área e renda per capita (Brasil, MDS, 2014). Por meio do diagnóstico populacional e demanda de vulnerabilidade e risco social será referenciada a unidade CRAS, que tem como base atendimento territorialidade, divididos por porte e áreas. 


\subsection{O CONCEITO DE ASSESSORIA E SUA DIMENSÃO ABERTA}

As diversas transformações sofridas pela sociedade instauram o imperativo de observá-la de maneira inovadora, buscando novas alternativas para compreender a complexidade dos processos de gestão instaurados em diferentes organizações e grupos sociais. Assim, as relações de trabalho também são ampliadas na atualidade, suas precisões de entendimento, de estudos, e de formas de atuação, configurando redes multidisciplinares, transdisciplinares e interdisciplinares.

Durante (2012) destaca que uma das profissões que se integra nesse cenário de transformação do conhecimento é o Secretariado Executivo. Segundo Nonato Júnior (2009, p. 24) "Este crescimento ocorreu, por exemplo, com os profissionais que têm por objeto de interesse as relações de assessoria. Uma vez que o assessor atua como polo articulador de vários profissionais e trabalha com conhecimentos de natureza diversa".

Assim, o conceito de assessoria remete à complexidade de atividades desempenhadas pelo secretário e, por isso, a assessoria manifesta a partir de diferentes realidades. Essa profissão torna-se "cada vez mais próxima das novas tecnologias e das demandas de mercado, revolucionando o papel dos assessores executivos." (Nonato Júnior, 2009, p. 32). Assim, o ato de assessorar remete ao estudo das relações, teorias e práticas envolvidas no desenvolvimento do conhecimento em Secretariado Executivo, em suas mais variadas áreas e conteúdos.

[...] é a dinâmica organizacional que significa o ato de recebê-lo, relacionando-o com o planejamento daquela ação, analisando sua viabilidade de execução em relação ao um plano organizacional maior, discutindo como tal ação poderá se incorporar a dinâmica das redes de suporte entre departamentos, pessoas e ideias. (Oliveira, 2011, p. 154).

Ainda de acordo com Nonato Júnior (2012, pp. 123-125), a assessoria é uma atitude gestora, ressalvando que o conceito de assessoria não é um conceito simplista fechado em si, mas complexo que se diferencia de noções meramente operacionais ligadas à assistência ou auxílio.

De acordo com Oliveira (2011) o termo assessoria está presente em diversos meios para designar processos de organização militar, governos, centros científicos, parlamentares, ambientais e nos movimentos sociais. Aquilo que o caracteriza enquanto conceito é a ideia de gestão articulada a diferentes ações e atores sociais.

Nonato Júnior (2009) aponta que dentre as muitas possibilidades de estudo das assessorias estão aquelas denominadas como "assessorias abertas". Inovadoras, elas trazem 
um viés que permite a análise de fenômenos sociais na realidade de trabalho do profissional de Secretariado Executivo. As assessorias abertas referem-se às práticas do profissional que vão além das organizações formais. Uma prática de diálogo entre as áreas de conhecimento, sendo inter, multi, pluri e transdisciplinar. Seu caráter interdisciplinar se realiza por meio da troca de conhecimentos entre diferentes áreas e disciplinas, quanto a dimensão multidisciplinar e pluridisciplinar se configura nos projetos, esforços conjuntos entre diversos campos do saber em busca de um conhecimento multifacetado que envolva atividades de assessoria. Sua condição transdisciplinar baseia-se na articulação entre estudo científico e prática social, configurando-se como assessoria em áreas pioneiras e coevolutivas que é o diálogo com o desenvolvimento social e científico (Nonato Júnior, 2009). Neste contexto, “a transdisciplinaridade permite realizar os fundamentos teóricos da assessoria com situações do contexto social." (Crotti, 2011, p. 9)

Na perspectiva da assessoria aberta, este trabalho se enquadra no que se observa o fato do secretariado e o seu envolvimento nos trabalhos sociais, no desenvolvimento social e nas suas demandas científicas, sua dinâmica de multidisciplinaridade e a capacidade de dialogar com teoria e prática, de vislumbrar o que está empírico em diálogo com conceitos científicos.

\section{METODOLOGIA}

Entende-se que a apropriação da teoria leva ao exercício da análise da prática, tendo como ponto de partida o método científico "como conjunto de procedimentos intelectuais e técnicos adotados para se atingir o conhecimento" (Gil, 2012, p. 8), que se inicia na escolha do fenômeno a ser estudado percorrendo o caminho da aparência à essência do fenômeno.

Sob a óptica do método dialético, tendo em vista, que serão estudados o CRAS e a assessoria aberta, enfocando a atuação de trabalho com a realidade social, a busca de encontrar meios de intervenção que modifique a realidade das famílias usuárias do CRAS, permeia o fato de se reconhecer primeiramente a realidade do instrumento CRAS, para que se possam desenvolver meios de trabalho junto com as famílias. Nesta perspectiva, Gil (2012, p. 14) indica a dialética como método de articulação entre realidade social e científica, uma vez que "a dialética fornece as bases para uma interpretação dinâmica e totalizante da realidade, já que estabelece que os fatos sociais não podem ser entendidos quando considerados isoladamente, abstraídos das suas influências políticas, econômicas, culturais etc."

Assim, observa-se que o método dialético associa-se com a assessoria aberta, uma vez que o dialético compara realidades e diferentes contextos, enquanto que a assessoria aberta

Revista de Gestão e Secretariado - GeSec, São Paulo, v. 6, n. 3, p 46-69,set./dez. 2015. 
também trabalha com esses aspectos de articulação da realidade em rede. Ambos convergem na procura do homem em desvendar o empírico em diálogo com conceitos científicos, concebendo e debatendo os fatos, de maneira a fomentar teorias sobre os assuntos, "fortaleceu-se a ideia de que o conhecimento era produzido pelo homem de acordo com suas provocações intelectuais." (Nonato Júnior, 2009, p. 53)

De acordo com Minayo (2008), a visão da realidade, desde sua concepção a partir do empírico até a formulação do conhecimento científico mediante o fenômeno causador da problemática, exige embasamento teórico, o qual é obtido por intermédio da pesquisa científica, configurada como premissa da ciência para revelar o que é intrínseco no cotidiano do ser humano em sociedade, mesmo que de forma incompleta, devido à constante transformação da realidade.

Assim, a execução da pesquisa se caracteriza por trabalho de natureza exploratória, levando em consideração o caráter sistematizado e investigativo sobre o tema. Para Minayo (1994, p. 32), a pesquisa exploratória sistematiza-se na "escolha do tópico de investigação; a delimitação do tema; a definição do objetivo; a construção do marco teórico conceitual; a escolha dos instrumentos de coleta de dados, a exploração de campo”. A abordagem é o método qualitativo que "[...] caracteriza-se pela empiria e pela sistematização progressiva de conhecimento até a compreensão da lógica interna do grupo ou do processo em estudo [...]" (Martinelli, 1999, p. 57), ou seja, a relação do pesquisador com o objeto de estudo, possibilitando a percepção de fatos oriundos da experiência e que se mostram relevantes para a pesquisa.

O roteiro de entrevista utilizado neste estudo apresentou-se com um número de cinco pontos de discussão pré-formuladas estruturadas da seguinte forma: os serviços prestados no CRAS; a distribuição dos serviços no território (divisão urbano e rural), os desafios enfrentados pelo CRAS na aplicação dos serviços, a gestão de trabalho no CRAS e a assessoria aberta prestada pela equipe de trabalho. O critério para eleição desses pontos baseou-se nas temáticas centrais enumeradas no sistema de gestão do CRAS.

A entrevista foi aplicada com a equipe de referência de um instrumento CRAS em um município de médio porte da região centro-sul do Paraná, para evidenciar elementos que inserem à assessoria aberta do secretariado executivo à gestão do Centro de Referência da Assistência Social - CRAS, como meio de intervenção profissional na implantação e implementação dos serviços.

A entrevista foi realizada com os técnicos de nível superior que fazem parte da equipe central de referência na sede do CRAS, criteriosamente escolhidos por conhecerem a 
logicidade do que é o instrumento CRAS por meio dos documentos existentes, e por conhecerem a realidade apresentada na prática, que envolvem as questões de funcionamento e gestão das ações desenvolvidas.

Convém ressaltar que os entrevistados tiveram um breve esclarecimento sobre a finalidade da pesquisa, e que não possuíam obrigação de respondê-la. Há, também, o Termo de Consentimento livre e esclarecido ficando, a critério do entrevistado participar ou não do estudo. Com isso, dos quatro técnicos solicitados a participar, três aceitaram e um não estava presente no local no momento da entrevista, obtendo-se $75 \%$ de retorno das respostas.

Os integrantes da equipe que compõe o CRAS observado neste estudo serão referenciados de diferente maneira, como sendo: assistente social da equipe central e psicóloga da equipe central. Quanto à equipe volante, que atua na zona rural, a entrevistada será aqui referenciada como assistente social da equipe volante.

A elaboração desta pesquisa recorreu, ainda, à pesquisa bibliográfica e análise documental das matérias que não recebem ainda um tratamento analítico, ou que ainda podem ser reelaborados de acordo com os objetos da pesquisa" (Gil, 2009, p. 115), contidos no site do Ministério do Desenvolvimento Social - MDS, na biblioteca particular de leis, resoluções, deliberações e congêneres a respeito do tema.

\section{ANÁLISE DOS RESULTADOS}

\subsubsection{DISCUSSÃO DOCUMENTAL: PERFIL DO CRAS E DA EQUIPE GESTORA}

A partir do estudo documental, foi possível observar conteúdos a convergirem para duas categorias: os serviços prestados no CRAS e as equipes de referência e gestão do trabalho. A primeira é importante para apresentar quais serviços demandam atividades de assessoria e a segunda para compreender o papel da equipe que deverá executar a gestão do centro. Acerca dos serviços, O CRAS possui três tipos principais:

a) Serviço de Convivência e Fortalecimento de Vínculos - SCFV tipificado como realização de grupos de convivência, baseados nas demandas que se apresentam, garantindo que progressivamente os usuários consigam protagonizar suas vidas, complementando, assim, o trabalho social com as famílias prevenindo o risco social;

b) Serviço de Proteção e Atendimento Integral à Família - PAIF tipificado como trabalho Revista de Gestão e Secretariado - GeSec, São Paulo, v. 6, n. 3, p 46-69,set./dez. 2015. 
social realizado com as famílias, de forma continuada, para fortalecer a proteção destas, impedindo que haja ruptura de vínculos, e garantir o acesso aos direitos sociais, com objetivo de melhorar a qualidade de vida dessas famílias;

c) Serviço de Proteção Social Básica no Domicílio para Pessoas com Deficiência e Idosos. "O serviço tem por finalidade a prevenção de agravos que possam provocar o rompimento de vínculos familiares e sociais dos usuários." (Brasil, Tipificação Nacional de Serviços Sócioassistenciais, 2009, p. 16)

Além da prestação de serviços a usuários, o CRAS também realiza o mapeamento e a organização da rede socioassistencial (organizados da seguinte maneira: vigilância social, proteção social e defesa social e institucional) de proteção básica, para inserir as famílias nos serviços de assistência social local, e outras políticas públicas, pois, realiza busca ativa, e necessita da rede de serviços para encaminhamento de demandas que se fazem necessárias. Também se faz imprescindível o envolvimento de todos os profissionais nas diversas áreas de atuação para que tais ações se coordenem em um resultado positivo na ação final que se coloca dentro da realidade dos indivíduos.

Neste instrumento público, o cuidado com a competência de cada setor é fundamental, apesar de a intersetorialidade ser essencial, o fato de que não pode haver contradições quanto à gestão dos serviços e a organização da rede sócio assistencial que é função do CRAS e a gestão do Suas que é função do órgão gestor. Toda esta prática exige que o instrumento CRAS possua profissionais que reconheçam essa realidade, que se posicionem de maneira a buscar formas concretas em intervir em cada demanda que se apresenta. Por se tratar de um instrumento de assistência social que, como acima citado, trabalha com a questão social, com os paradigmas da pobreza e das dificuldades dos indivíduos.

\section{1.2 EQUIPES DE REFERÊNCIA: GESTÃO DE TRABALHO}

Observa-se o fato que se diferenciam equipe de referência e famílias referenciadas (aquela que vive em áreas caracterizadas como de vulnerabilidade, definidas a partir de indicadores estabelecidos por órgão federal, pactuados e deliberados), para melhor entender o contexto do estudo, focado na equipe de referência e não no usuário da política e do instrumento, considerando o objetivo de análise da gestão realizada pela equipe. A equipe de referência dos CRAS pequeno porte I, é composta por um assistente social, um psicólogo

Revista de Gestão e Secretariado-GeSec, São Paulo, v. 6, n. 3, p 46-69, set./dez. 2015. 
preferencialmente, dois técnicos de nível médio, e um coordenador (Brasil,Suas/PR: instrumentos legais, s/d, p. 201).

Em território de extensão rural ampla, como o caso do município analisado, cabe a composição de mais uma equipe técnica na mesma configuração, com exceção do coordenador, denominada equipe volante ou itinerante (BRASIL, Suas/PR: instrumentos legais, s/d, p. 201). Trata-se de equipes multidisciplinares que unificam ações para prestação dos serviços oferecidos nos CRAS. Sobre as equipes volantes, o MDS dispõe que:

\begin{abstract}
A constituição de equipe volante se aplica a municípios que já tenham implantado pelo menos um CRAS e cujo território é extenso, em especial com presença de comunidades rurais ou tradicionais e que podem ter como características a alta dispersão populacional, presença de comunidades isoladas e ou de difícil acesso, com prioridade para aquelas em situação de extrema pobreza e que precisam ser alcançadas pelos serviços sócio assistenciais de proteção básica. (Brasil, MDS, 2014)
\end{abstract}

Cada profissional possui atribuições específicas no âmbito do CRAS, os técnicos de serviço social e psicologia devem ofertar serviços como acolhida e informação sobre os encaminhamentos, planejar, programar e mediar PAIF no território de abrangência, realizar atendimentos particularizados às famílias, dinamizar o desenvolvimento comunitário por meio de atividades coletivas, dar suporte técnico e acompanhamento aos profissionais envolvidos no SCFV, realizar busca ativa das demandas, acompanhamento dos programas sociais, articulação e encaminhamentos à rede de serviços sócio assistências (Brasil, Orientações Técnicas Centro de Referência de Assistência Social - CRAS, 2009, p. 64)

São atribuições do coordenador do CRAS: fazer parte da implantação do instrumento e de seus programas, serviços e projetos; coordenar o monitoramento da execução dos serviços, participar da sua avaliação, coordenar a execução das ações, mantendo diálogo entre profissionais, famílias envolvidas nos serviços e rede sócio assistencial; definir, juntamente com a equipe, critérios de inclusão, acompanhamento e desligamento das famílias usuárias;promover e articular os serviços de transferência de renda envolvidos no CRAS; mapear o território e participar da avaliação do órgão gestor, participar dos processos de articulação intersetorial, e realizar a gestão do CRAS de forma plena em diálogo constante com os demais setores, e a equipe. (Brasil, Orientações Técnicas Centro deReferência de Assistência Social - CRAS, 2009, p. 64)

Dessa maneira é feita a distribuição de serviços dentro das equipes de referência do CRAS, entre profissionais executores das ações que permeiam os serviços de coordenação das ações, serviços e gestão do CRAS. Na perspectiva da assessoria “[...] para organizar, 
selecionar, assistir e encaminhar fontes de saber é necessário estar assessorado por outras pessoas.” (Nonato Júnior, 2009, p. 80)

\subsection{DISCUSSÃO E ANÁLISE DE CAMPO}

Conforme observado em campo, as duas categorias mapeadas nos documentos acerca de "serviços" e "gestão" do CRAS também se revelam empiricamente como principais debates a serem empreendidos a fim de compreender a assessoria aberta realizada com viés social a partir da investigação das quatro questões citadas na metodologia e que serão retomadas nas análises a seguir.

\subsubsection{Serviços}

Em entrevista foi perguntado inicialmente aos membros da equipe sobre os serviços prestados no CRAS. As entrevistadas expressaram que os serviços prestados no CRAS, são de fortalecimento de vínculos comunitários e familiares, de intervenção no cotidiano dos indivíduos na busca de propiciar a efetivação dos direitos sociais.

A psicóloga da equipe volante afirma:

os serviços prestados incluem ações preventivas, consciência e socialização, inserção e acolhida, capacitação e inserção produtiva, apoio e acompanhamento familiar, e todos esses serviços estão agrupados nas ações do PAIF e do SFVC.

Segundo a assistente social responsável pela equipe central e também coordenadora, os serviços são:

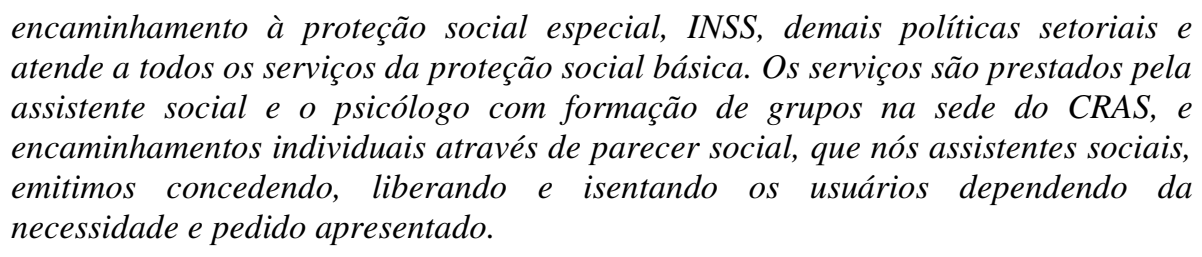

A assistente social responsável pela equipe volante coloca que os serviços dispostos no CRAS são:

os benefícios eventuais, PAIF, SCFV (crianças, adolescentes, jovens, idosos) e busca ativa de situações que se configuram como vulnerabilidade e risco social.

Percebe-se na fala das entrevistadas que os serviços estão conforme visto na tipificação citada anteriormente, seguem uma linha de atuação em conformidade com o que aparece e atende ao que está previsto. Não indo além de encaminhamentos individualizados e

Revista de Gestão e Secretariado - GeSec, São Paulo, v. 6, n. 3, p 46-69, set./dez. 2015. 
atendimentos grupais formam uma estatística. A assistente social da equipe central ao completar sua resposta sobre os serviços diz que:

os serviços são prestados a quem procurar. Temos metas a serem cumpridas, para
preenchimento do sistema, temos previsto o atendimento de 250 famílias
mensalmente no serviço de fortalecimento de vínculos, dividimos os grupos em
gênero e atendemos cada integrante da família em grupos diferentes para trabalhar
cada um dentro do que lhe é o papel no âmbito família e nesses grupos eles dividem
experiências. Já o PAIF é o individual, a visita domiciliar, é o usuário e sua
demanda própria."

Mediante o exposto acima, vê-se que há efetividade no que prevê a Política Nacional de Assistência Social - PNAS no que se refere ao CRAS: a prestação e orientação por parte do CRAS às famílias usuárias sobre os serviços ofertados, a execução das ações que visem o acesso das famílias aos serviços, a garantia dos direitos, e a promoção do fortalecimento dos vínculos e protagonismo do usuário. (Brasil, PNAS, 2005).

Percebe-se que o intuito dos serviços é retirar os usuários e suas famílias da vulnerabilidade social em que se encontram, seja ela já prolongada em relação à situação vivida por fatos, ou que se apresenta de imediato através de um fator pontual que se expressa em algum acontecimento.

A assistente social da equipe central completa sua resposta sobre os serviços dizendo:

cada serviço prestado é feito observando e escutando o usuário, por exemplo, fazemos encaminhamentos ao INSS e esses encaminhamentos podem ser para BPC ao deficiente, e auxílio doença. Precisamos ouvir o usuário, e ajudá-lo a identificar se o que está acontecendo na vida dele.

Nessa fala, identifica-se que a rede de atendimento se estende quando se observa os encaminhamentos feitos pelos profissionais. Vai além do município, e se funde com Estado e União no intuito da garantia de direitos. Na sequência, foi perguntado sobre a distribuição dos serviços no território, buscando compreender a ramificação das redes de assessoria envoltas na gestão. A psicóloga da equipe volante do CRAS diz que:

o CRAS do município é dividido em CRAS sede responsável pelos usuários que residem na cidade e é composto por uma assistente social e psicólogo. E o CRAS volante que atende os usuários que moram nas localidades do interior e também contém assistente social e psicólogo.

Segundo a assistente social da equipe volante, a divisão dos serviços se faz por território urbano e rural, o rural por meio da equipe volante que realiza a busca ativa das demandas amenizando a dificuldade dos usuários das áreas de difícil acesso, de acessar as políticas públicas ofertadas no município. Sob essa perspectiva, o trabalho de gestão social não é visto como um trabalho fechado no escritório, mas como um trabalho de campo no qual os processos gestores se constroem a partir de colaboração da equipe, ou seja, de redes de 
assessoria estabelecida entre os profissionais, as metas, os projetos e atividades por eles desempenhados.

Nesse sentido, a assistente social da equipe volante reitera que a dinâmica social do trabalho e a dinâmica de funcionamento da equipe devem seguir o preceito da mobilidade e da partilha coletiva do trabalho. Assim, não há uma gestão isolada ou centralizada em um fato ou pessoa, mas uma rede aberta de processos de assessoria que se constituem como elemento para os processos gerenciais assessoria aberta "gera resultados positivos quanto às metas que o CRAS possui e ao resultado final com o usuário do centro”.

Em suma, é possível avaliar que o CRAS oferece serviços que podem modificar as estruturas familiares no que diz respeito à convivência familiar e comunitária, também auxilia as famílias e seus indivíduos na superação dos seus problemas, fazendo com que, assim, não fiquem em situação de vulnerabilidade social, tornando-se protagonistas da própria vida, deixando de depender da política de assistência social como proteção e garantia de sobrevivência.

\subsubsection{Gestão do CRAS: diálogos com assessoria aberta}

Durante a entrevista pode-se observar que há desafios os quais as equipes enfrentam. Segundo elas, estes desafios podem ser amenizados, se não resolvidos, com a efetivação e um melhor entendimento do que são os serviços do CRAS. A função dentro da política da assistência social e a efetivação da gestão do trabalho, itens que se bem entendidos poderão fazer a diferença nos resultados finais só serão efetivados se a gestão do CRAS for interpretada de maneira correta. Quando se questionou à assistente social e coordenadora do CRAS sobre os desafios enfrentados pelo CRAS na aplicação dos serviços, ela destacou:

\footnotetext{
o maior desafio é o entendimento que se faz necessário sobre o CRAS. Os gestores acabam por não entender o formato de atendimento do instrumento, a distribuição de funções e que a gestão do trabalho deve ser feita de forma contínua e em conjunto com o órgão gestor da política, tem que efetivar a gestão social no nosso município, principalmente nas ações do CRAS.
}

A assistente social da equipe volante também destaca que o desafio está na complexidade da gestão dos serviços, pois se trata de serviço que reúne simultaneamente gestão municipal, estadual e nacional; além de constante fluxo de atividades entre o centro e o campo, criando-se uma rede complexa de relações a serem compreendidas tanto pela equipe como pelos usuários. A psicóloga da equipe volante acrescentou que:

vejo como maior dificuldade a inserção dos usuários aos grupos de convivência e fortalecimento de vínculos, a dificuldade de acesso em muitas localidades, e a

Revista de Gestão e Secretariado - GeSec, São Paulo, v. 6, n. 3, p 46-69,set./dez. 2015. 
dificuldade que os usuários têm de compreender a diferença entre assistente social e psicólogo.

Sendo assim, identifica-se que a gestão social no instrumento CRAS é de importantíssimo para que os serviços se efetivem. As entrevistadas unificam o pensamento de que não há atenção voltada para esse fator e isso está dificultando o cotidiano de ação dos profissionais. Isso se vincula com a assessoria aberta de forma que um profissional específico, para atuar nesta função faria com que esta questão de gestão/coordenação do CRAS, que algumas vezes fica ausente em decorrência de um profissional ter dupla função, apareça e seja prestada de forma eficiente, fazendo com que cada profissional atue em sua devida área.

A assistente social da equipe central expõe que o funcionamento da equipe é complexo, havendo necessidade de um profissional capaz de assessorar a rede de membros envolvidos no trabalho do CRAS

outro desafio é que sou assistente social e coordenadora do CRAS, e é bem difícil
conseguir conciliar a coordenação com a função de assistente social da equipe [...].
Como assistente social, presto atendimento direto ao usuário, e preciso participar
das atividades do CRAS. Como coordenadora deveria fazer a gestão social do
trabalho, fazer o diálogo com o órgão gestor e com os demais setores, para efetivar
a rede socioassistencial, planejar as ações, buscar a capacitação continuada da
equipe, coordenar, mas quando faço um acabo deixando descoberto outro. Como o
usuário é nossa prioridade, a gestão social passa somente pelo órgão gestor, que
não está aqui dentro do CRAS e acaba por planejar as ações e muitas das vezes não
se concilia com a nossa realidade.

É diante deste contexto que a abertura para que profissionais de Secretariado Executivo façam parte de equipes de trabalho desta natureza, pois se tratam de profissionais capazes de realizar uma gestão para a assessoria do trabalho de equipes, projetos, metas e atividades coletivas; não apenas executando atividades, mas realizando planejamento estratégico, planos de assessoria e articulação institucional (Nonato Júnior, 2009).

Mediante o exposto, pode-se observar que existe o desafio da efetivação da gestão social do CRAS devido à natureza complexa das atividades de gestão e à ausência de profissional específico para assessoria deste trabalho. Percebe-se, no decorrer da pesquisa, que o CRAS é um instrumento de dissipação de demanda, ou seja, busca emancipar seus usuários por meio de encaminhamentos a órgãos os quais se identifica emergência de atendimento. Para isso, é necessário que venha a ser feito um diálogo entre os setores, para que se defina a ação de cada profissional, e não venha a haver, como citado pela técnica, a interferência negativa de profissional a profissional na hora da realização das ações. Outro fator observado refere-se à contraditoriedade quando se referencia pelas técnicas o serviço de informação ao usuário e a dificuldade de que o usuário participe das ações. 
De acordo com Oliveira (2011), pode-se remeter à assessoria aberta, no que tange a uma assessoria de recursos humanos e gestão de equipes, a qual obtém organização de recursos materiais e humanos, havendo equilíbrio entre eles, para que proporcione benefícios na produção.

\subsubsection{Gestão social em rede e demandas por assessoria aberta}

As entrevistadas salientam, ao longo da pesquisa, que o processo gestor do CRAS é desafiador, pois não está centralizado em um único núcleo. Ele é complexo, polissêmico, desenhando-se enquanto rede de relações entre atores sociais, membros da equipe gestora e escalas políticas nacionais, estaduais e municipais.

Desta forma, sinaliza-se a necessidade de um trabalho a partir de dinâmicas abertas que envolvam essa gestão social na perspectiva das assessorias que, conforme assinaladas por Nonato Júnior (2009), são estruturas de gestão em rede que visam à articulação de diferentes atores e práticas de grupos sociais, organizações, projetos e metas.

Quando a equipe assinala que "o assistente social presta orientação e auxílio a tudo o que envolve a defesa dos direitos humanos", aponta para a necessidade de que a gestão do CRAS seja crítica, pensada não apenas enquanto concepção organizacional, mas também social. Por isso, o diálogo com assessoria aberta se amplia, uma vez que esta proposta de assessoria se vincula à gestão crítica de espaços sociais, políticos, culturais e ambientais.

Também, acrescenta-se que um profissional dedicado ao trabalho de assessoria no CRAS pode efetivar o diálogo entre os setores, objetivando metas a serem cumpridas e os serviços a que seus usuários possam ser encaminhados não apenas na execução de serviços, mas no planejamento, estratégia e seu plano de metas.

Pode-se observar que o funcionamento da gestão social do CRAS deixa espaço para trabalhos de assessoria com viés social. Mais uma vez se vê que os profissionais do CRAS sentem a necessidade de uma maior articulação da gestão, no sentido de melhor organizar serviços, processos, metas e projetos partilhados coletivamente pela equipe. Assim, apresentase a falta de uma assessoria com viés social na gestão do CRAS, com a finalidade de aperfeiçoar tanto os serviços para os usuários como para os profissionais envolvidos nas políticas socioassistenciais envolvidas na rede.

A partir desta perspectiva gestora, as determinações da gestão de trabalho têm por finalidade alcançar os objetivos da política nacional de assistência social, ou seja, garantir que os serviços prestados sejam de boa qualidade e, a partir disso, escolher os meios para alcançar

Revista de Gestão e Secretariado - GeSec, São Paulo, v. 6, n. 3, p 46-69,set./dez. 2015. 
os direitos dos usuários do Suas, capazes de beneficiá-los. (Brasil, NOB-RH/Suas: anotada e comentada, 2011)

A assistência social se apresenta, principalmente no âmbito do CRAS, como multidisciplinar. Nesse foco, percebe-se que o ordenamento de serviços do CRAS não é unicamente função do assistente social. O coordenador do CRAS, segundo a NOB/RH/Suas, tem como exigência ensino superior e conhecer os assuntos e temas da política, tendo a mínima experiência na área.

Essa conotação acerca da assistência social, a demanda que se trabalha no âmbito do CRAS, seus serviços, a gestão social do CRAS e a assessoria social, exige que a assessoria de serviços seja efetiva. A assistente social da equipe central e coordenadora do CRAS coloca no final de sua fala que:

essa assessoria de que falamos eu e a psicóloga, se feito por outro profissional, que somente exerça a função de coordenador, amarraria melhor os serviços e trabalhos e faria com que cada coisa caminhasse como deveria, sem ter que parar um serviço para realizar outro, deixando, sempre algo em aberto.

Nesse sentido, retorna-se à dimensão que remete a assessoria aberta que já ocorre informalmente no grupo do CRAS por meio de colaboração coletiva entre membros da equipe, demandando para melhoria de suas práticas de gestão uma ampliação deste processo, tornando "explícito" o potencial "tácito" dos trabalhos de assessoria junto a grupos sociais uma vez que sua amplitude e valor referem-se também "à dimensão dos conhecimentos e dos ativos intangíveis" (Nonaka \& Takeuchi, 2006).

Assim, a necessidade de ampliar e articular os processos de gestão social do CRAS a partir das perspectivas das assessorias abertas é, também, uma forma de democratização dos serviços. Dessa forma, contribuir para a redução da vulnerabilidade e risco social e para que os serviços sejam oferecidos de maneira correta e, ainda, possam ser visualizadas as potências e demandas que poderão surgir, e que já exista um planejamento de ações para enfrentá-las (Nonato Júnior, 2012).

\section{CONCLUSÕES}

Ao analisar transversalmente o conteúdo abordado neste artigo, percebe-se que a organização dos dados converge para a montagem da assessoria aberta como estratégia articuladora da gestão social do CRAS. Uma representação deste processo é exposta na figura abaixo:

Revista de Gestão e Secretariado - GeSec, São Paulo, v. 6, n. 3, p 46-69,set./dez. 2015. 


\section{Figura 1 - Rede de assessoria e gestão do CRAS}

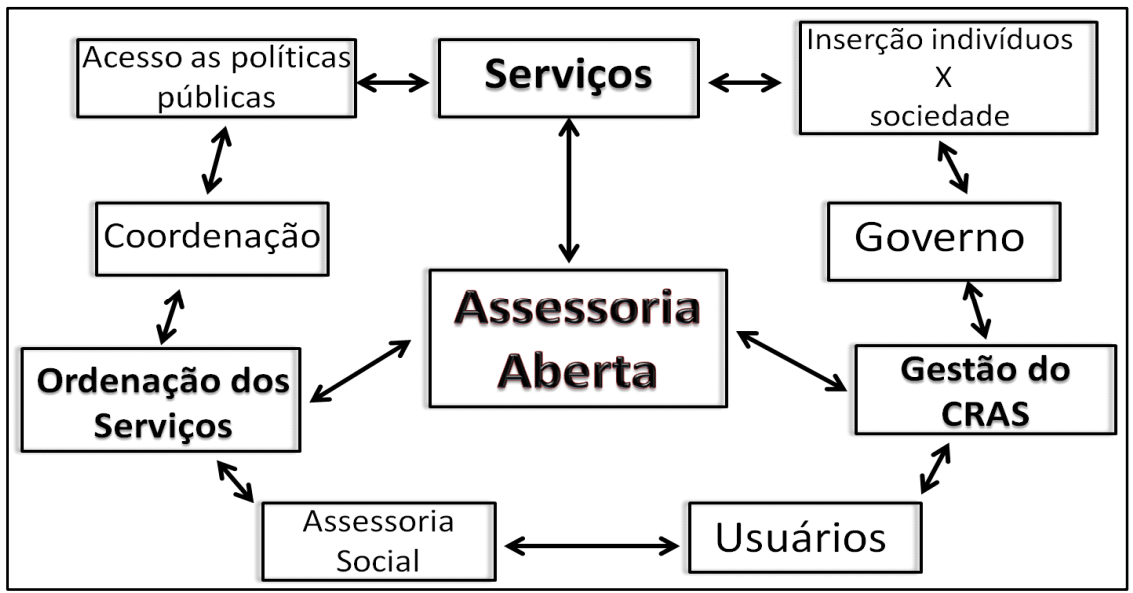

Fonte: Elaborado pelos autores (2015).

No contexto do CRAS, entende-se que a assessoria aberta é o espaço de articulação entre a gestão e as questões sociais. Evidencia-se a dimensão social, os fatores que corroboraram para as relações entre o CRAS com a sociedade, relacionando-o com a rede em que está inserido.

No tangente à gestão, a coordenação do CRAS apresentou-se como um elemento determinante das relações entre o próprio instrumento CRAS com as técnicas de planejamento e de relacionamento interno e externo que incluem suas perspectivas e desafios a serem realizados, apontando a necessidade de atividades de assessoria para articular a gestão entre diferentes sujeitos e instâncias.

Primeiramente, observa-se que toda a dinâmica do CRAS se configura em um instrumento de atuação frente à população usuária dos serviços em seu território de origem, tendo na equipe articuladora o foco de sua gestão.

No decorrer da pesquisa foi possível verificar a existência de lacunas no que se refere às equipes. $\mathrm{O}$ desenho norteador do CRAS é estruturado, prevendo ações que, se trabalhadas de maneira correta, podem intervir na realidade das famílias e da comunidade. Mas essa gama de serviços precisa ser assessorada de forma a obterem-se resultados benéficos. Considerando que a população usuária apresenta vulnerabilidade, faz-se necessário não fragmentar o trabalho da gestão, investindo em processos de gestão em rede, articulados pela lógica das assessorias abertas.

Cada técnico tem sua função específica, o assistente social trata das questões sociais que se apresentam, fazendo a leitura delas e as encaminhando às suas origens para solucionálas ou promover o enfrentamento. O psicólogo formula grupos que, por meio de dinâmicas e 
observação, aos poucos incentivam o convívio familiar e comunitário. Os auxiliares administrativos promovem o acolhimento dos usuários e relacionam a mediação entre gestão e prática social. O coordenador deve promover a gestão social do CRAS e o ordenamento dos serviços para que assim os recursos advindos do Estado e da União sejam aplicados corretamente e alcancem os resultados esperados com os usuários, que é a redução/anulação da vulnerabilidade e risco social.

Assim, para que os serviços sejam oferecidos de forma correta e possam ser visualizadas as potenciais demandas que poderão surgir, e se já existe um planejamento de ações para enfrentá-las, têm-se um perfil de gestão, que abre um espaço entre a gestão social e a gerencial do CRAS. Esse espaço de articulação deve ser preenchido com a assessoria aberta, que se percebe materializada nas práticas do CRAS, mas não institucionalizado.

A complexidade da gestão social dos serviços do CRAS, como já observado, mostra a necessidade de observar as várias formas de utilizar a assessoria aberta de maneira a contribuir para que esse equipamento elabore possibilidades de ação mais concretas e consiga sistematizar ideias formulando e planejando de maneira eficaz essas atuações. De maneira geral, que esta contribuição também venha a possibilitar que a sociedade se aproprie mais deste instrumento e para que a instituição se compreenda melhor. E que possibilite, também, a permissão de encontrar meios de implementar os serviços existentes e de implantar novos, visando à melhoria no atendimento das demandas que se apresentam nos instrumentais do CRAS.

O profissional de Secretariado Executivo possui em seu perfil algumas atribuições e especificidades que o torna capaz de atuar como mediador onde quer que esteja inserido. E, no contexto acima estudado, este profissional se faz de fundamental importância, pois assume papel diversificado como articulador entre questões sociais e gerenciais.

Para ter este perfil, o profissional de Secretariado Executivo, além das características advindas da sua formação, necessita se adequar a algumas situações que exijam articulação com demandas sociais, gestão das informações em setores públicos e no terceiro setor, ter pró-atividade e sempre estar na busca pelo aprendizado contínuo. (Almeida; Rogel \& Shimoura, 2010)

Por fim, partilha-se do entendimento de Nonato Júnior (2009, pp. 160-162) quando o autor discute que a assessoria aberta não se fixa apenas nas dimensões internas da empresa, mas busca "relação com outras áreas do conhecimento e realidades". Assim, conforme salienta o autor, a Ciência da Assessoria é um espaço de diálogo sobre as condições do conhecimento em Secretariado Executivo que, em construção, é aberto a incorporar diversas 
práticas sociais, culturais, intelectuais, políticas, ambientais, linguísticas e organizacionais na área secretarial.

\section{Referências}

Almeida, Walkíria Gomes de; Rogel Geórgia T. S \& Shimoura, Alzira da Silva (2010). Mudanças de paradigmas na gestão do profissional de secretariado. Revista de gestão e secretariado. São Paulo: vol. 1, n. 1, pp46-68, jan./jun. 2010.

Bauman, Jussara; Crotti, Katiane \& Silva, Kelly (2009). Assessoria Executiva na Educação Superior. Trabalho de conclusão de curso de graduação em Secretariado Executivo, orientação: Raimundo Nonato Júnior, Universidade Estadual do Centro-oeste (Unicentro).

Brasil. Ministério do desenvolvimento social e combate à fome - MDS (2011). Orientações técnicas centro de referência de assistência social - CRAS. Brasília.

Ministério do desenvolvimento social e combate à fome - MDS (2014). Benefício de

Prestação Continuada (BPC). Recuperado em 19 de maio, 2014, de $<$ http://www.mds.gov.br/assistenciasocial/beneficiosassistenciais/bpc $>$

Ministério do desenvolvimento social e combate à fome - MDS (2010). Política nacional de assistência social PNAS/2004. Norma operacional básica - NOB/Suas. Brasília.

Ministério do desenvolvimento social e combate à fome - MDS.Norma operacional básica NOB/Suas (2014): construindo as bases para a implantação do sistema único de assistência social. Recuperado em 18 de maio, 2014, de <http://www.mds.gov.br/assistenciasocial/arquivo/normaoperacional-basica-do-suas.pdf/view>

Ministério do desenvolvimento social e combate à fome - MDS (2014). CRAS institucional. Recuperado em 2 de julho, 2014, de <http://www.mds.gov.br/falemds/perguntasfrequentes/assistencia-social/psb-protecao-especial-basica/cras-centro-de-referencias-de-assistencia$\underline{\text { social/cras-institucional> }}$

. (s.d.). Ministério do desenvolvimento social e combate à fome - MDS. Suas/PR - Sistema único de assistência social:instrumentos legais.

- Ministério do desenvolvimento social e combate à fome - MDS (2009). Tipificação nacional de serviços socio assistenciais. Brasília.

Ministério do desenvolvimento social e combate à fome - MDS (2013) Norma operacional básica de recursos humanos do sistema único de assistência social - NOB-RH/Suas: anotada e comentada.Brasília, dezembro 2011. Reimp. 2013.

Ministério do desenvolvimento social e combate à fome - MDS (s/d). Centros de referência CRAS de assistência social. Caderno Suas IV: assistência social sistema municipal e gestão local do CRAS.

(2014). Lei $n^{\circ} 8.742$, de 7 de dezembro de 1993. Recuperado em15 de maio, 2014, de $<$ http://www.planalto.gov.br/ccivil_03/leis/18742.htm>

Constituição Federal, 1988. Recuperado em 16 de maio, 2014 de $<$ http://www.planalto.gov.br/ccivil_03/constituicao/ConstituicaoCompilado.htm>

Revista de Gestão e Secretariado - GeSec, São Paulo, v. 6, n. 3, p 46-69, set./dez. 2015. 
Couto, Berenice R (2006). O direito social e a assistência social na sociedade brasileira:uma equação possível? (3aed.). São Paulo: Cortez, 2006.

Crotti, Katiane (2010). Redes de assessoria executiva na extensão universitária. Guarapuava: Unicentro, 2010.

Durante, Daniela Giareta (2012). Pesquisa em secretariado: cenários perspectivas e desafios. Passo Fundo: UPF.

Gil, Antonio Carlos (2009). Como elaborar projetos de pesquisa (4a ed. - 12. reimp.). São Paulo: Atlas, 2009.

Luiz, Suianny Francini Conceição (2010). Assessoria transdisciplinar e redes de voluntariado:perspectivas em debate nas organizações religiosas.Paraná, 2010.

Martinelli, Maria Lúcia (1999). O uso de abordagens qualitativas na pesquisa em serviço social:Pesquisa qualitativa: um instigante desafio. São Paulo: Veras.

Minayo, Maria Cecilia de Souza (1994). Pesquisa social: teoria, método e criatividade (21aed.). Petrópolis: Vozes.

Abrasco.

(2008). O desafio do conhecimento:pesquisa qualitativa em saúde (11aed.) Rio de Janeiro:

Nonato Júnior, Raimundo (2009). Epistemologia e teoria do conhecimento em secretariado executivo: a fundação das ciências da assessoria. Fortaleza: Expressão Gráfica.

(2012). Objeto de pesquisa em secretariado executivo. In: Durante, Daniela Giareta. Pesquisa em secretariado: cenários perspectivas e desafios. Passo Fundo: UPF.

Oliveira, Saulo A (2011). Brevíssimo tratado conceitual da assessoria:para entender o secretariado. Guarapuava: Ideal.

Projeto de extensão rede educativa, empreendedora e colaborativa no Secretariado - Recosec (2011). Coordenação de Maria Luzitana Santos. Universidade Federal da Paraíba.

Silva, M. O. de; Yasbek, M. C \& Giovanni, G (2008). di. A política brasileira no século xxi: a prevalência dos programas de renda (4a ed. rev. atual.). São Paulo: Cortez.

(1999). Classes subalternas e assistência social. São Paulo: Cortez.

Sousa, Elaine Freitas de \& Luzitana, Maria (2012). Círculo de memória: um dispositivo de pesquisa para elaboração de inventário no projeto Recosec a partir de uma contribuição freireana (relato de pesquisa). Projeto de extensão Recosec: Universidade Federal da Paraíba (UFPB).

Zampier, Maika (2013). Assessoria a associações de beneficiários da reforma agrária - PB: implantação de gestão solidária e rede local. Projeto de Extensão da Universidade Federal da Paraíba (UFPB). 